\title{
Blunt trauma induced splenic blushes are not created equal
}

\author{
Clay Cothren Burlew ${ }^{1,2^{*}}$, Lucy Z Kornblith ${ }^{1}$, Ernest E Moore ${ }^{1}$, Jeffrey L Johnson ${ }^{1}$ and Walter L Biffl ${ }^{1}$
}

\begin{abstract}
Background: Currently, evidence of contrast extravasation on computed tomography (CT) scan is regarded as an indication for intervention in splenic injuries. In our experience, patients transferred from other institutions for angioembolization have often resolved the blush upon repeat imaging at our hospital. We hypothesized that not all splenic blushes require intervention.

Methods: During a 10-year period, we reviewed all patients transferred with blunt splenic injuries and contrast extravasation on initial postinjury $C T$ scan.

Results: During the study period, 241 patients were referred for splenic injuries, of whom 16 had a contrast blush on initial CT imaging (88\% men, mean age $35 \pm 5$, mean ISS $26 \pm 3$ ). Eight (50\%) patients were managed without angioembolization or operation. Comparing patients with and without intervention, there was a significant difference in admission heart rate (106 \pm 9 vs $83 \pm 6$ ) and decline in hematocrit following transfer (5.3 \pm 2.0 vs 1.0 $\pm 0.3)$, but not in injury grade ( $3.9 \pm 0.2$ vs $3.5 \pm 0.3)$, systolic blood pressure (125 \pm 10 vs $115 \pm 6$ ), or age (38.5 \pm 8.2 vs $30.9 \pm 4.7)$. Of the 8 observed patients, 3 underwent repeat imaging immediately upon arrival with resolution of the blush. In the intervention group, 4 patients had ongoing extravasation on repeat imaging, 2 patients underwent empiric embolization, and 2 patients underwent splenectomy for physiologic indications.

Conclusions: For blunt splenic trauma, evidence of contrast extravasation on initial CT imaging is not an absolute indication for intervention. A period of observation with repeat imaging could avoid costly, invasive interventions and their associated sequelae.
\end{abstract}

Keywords: Trauma, Injury, Spleen, Blush, Contrast extravasation, Angioembolization

\section{Introduction}

A contrast blush on computed tomography (CT) scan has been identified as a risk factor for failure of nonoperative management (NOM) of splenic injuries [1-3], prompting many centers to perform routine splenic artery angioembolization in the presence of a blush $[4,5]$. Using evidence of contrast extravasation on CT scan as an indication for angioembolization, however, has never been subjected to rigorous analysis. In our experience, patients with splenic injuries transferred from other institutions specifically for angioembolization have often resolved the blush upon repeat imaging at our hospital. This made us question whether all

\footnotetext{
* Correspondence: clay.cothren@dhha.org

${ }^{1}$ From The Department of Surgery, Denver Health Medical Center, Denver CO, USA

Full list of author information is available at the end of the article
}

postinjury splenic blushes were equivalent. Is evidence of contrast blush a mandate for intervention, or are there some injuries that cease active bleeding due to "internal tamponade" within the substance of the spleen? And how does one differentiate such patients? We hypothesized that not all splenic blushes require intervention and that patients may be selectively observed based upon physiologic status.

\section{Materials and methods}

During a 10 year period, all patients transferred from an outside hospital with blunt splenic injuries and evidence of active contrast extravasation on initial postinjury CT scan were evaluated. Patients undergoing intervention (angioembolization or splenectomy) were compared to those managed without intervention. Demographic data, laboratory values, vitals, intervention, and outcome were
Ciomed Central

(c) 2012 Burlew et al; licensee BioMed Central Ltd. This is an Open Access article distributed under the terms of the Creative Commons Attribution License (http://creativecommons.org/licenses/by/2.0), which permits unrestricted use, distribution, and reproduction in any medium, provided the original work is properly cited. 
analyzed. Patients with identified pseudoaneurysms were excluded. Statistical analysis was performed using SAS for Windows (SAS Institute, Cory, NC); p-value $<0.05$ was considered statistically significant. The Colorado Multi-Institutional Review Board approved this study.

\section{Results}

During the study period, 241 patients with splenic injuries were transferred from an outside hospital, of which 16 had a contrast blush on CT imaging. All contrast blushes were intraparenchymal. The majority $(88 \%)$ of patients were men with a mean age of $35 \pm 5$ and mean ISS of $26 \pm 3$. Mean time of transfer to Denver Health following injury and evaluation at an outside hospital was $6.4 \pm 1.5 \mathrm{~h}$. One patient received 1 unit of packed red blood cells during transfer. No patient reported use of anticoagulant or antiplatelet medications. Eight (50\%) of these sixteen patients were managed without angioembolization or operation. In the group not undergoing intervention, Focused Abdominal Sonography for Trauma (FAST) examination was positive in six and negative in two patients. In patients undergoing intervention, FAST was positive in two patients and was not performed in the remainder. The two groups of patients had similar splenic AAST injury grades, age, injury severity scores, and emergency department systolic blood pressure (Table 1). The amount of intraperitoneal blood did not appear to be different between the two groups. The group managed without intervention had 1 patient with left upper quadrant (LUQ) blood, 5 patients with bilateral upper quadrant (BUQ) free fluid, and 2 patients with blood extending into the pelvis. In the group undergoing intervention, 3 patients had BUQ free fluid, and 3 patients had blood extending into the pelvis; the remaining 2 patients had no comment of intraperitoneal free fluid noted. In patients undergoing intervention there was a significant difference in admission heart rate and decline in hematocrit following transfer compared to patients who did not require operation or angioembolization (Table 1).

In the $8(50 \%)$ patients managed with observation, 3 underwent repeat imaging immediately after transfer; CT scan revealed the blush had resolved (Figure 1). None required blood product transfusion. Of these 8 patients there was 1 complication; a 49 year-old man with a grade III splenic laceration which had been stable without extravasation on repeat CT scan imaging had a delayed bleed on hospital day \#4 treated with angioembolization. Eight (50\%) patients underwent intervention following transfer (5 angioembolizations and 3 splenectomies). Two patients underwent immediate angiography without repeat $\mathrm{CT}$ scanning; although there was no evidence of contrast extravasation they underwent empiric main splenic artery embolization. Four patients had evidence of ongoing extravasation on repeat CT scan imaging and underwent intervention ( 3 angioembolization and 1 splenectomy). Two patients underwent immediate splenectomy upon arrival to DHMC based upon clinical indices. The eight patients received a mean of $3 \pm 1.6$ units of packed red cells during hospitalization. None of the eight patients had a splenic related complication. There were no significant differences in ventilator days, ICU length of stay, or hospital length of stay between the intervention and observation groups.

\section{Discussion}

Angioembolization has been reported to increase the success rates of NOM of splenic injuries [5-10]. One scenario which is considered by some to be an absolute indication for angioembolization is the hemodynamically stable patient demonstrating a contrast blush on admission CT scan. It is a logical presumption that evidence of arterial bleeding, a contrast blush, seen on CT imaging would decrease the likelihood of spontaneous hemostasis. In fact, patients with a splenic injury and an associated contrast blush are reportedly 24 times more likely to fail NOM [1]. Further study by Federle et al. noted a $19 \%$ incidence of contrast blush in their patient population of which only $7 \%$ were successful in NOM [2]. Therefore, angiography for patients manifesting a blush associated with their splenic injury has been recommended [11]. However, these data do not answer the question of whether all patients with evidence of contrast extravasation from splenic injury mandate intervention. Angioembolization is invasive, costly, and complications occur in over $20 \%$ of patients $[8,12-14]$.

Table 1 Patient demographics and injury characteristics stratified by management technique

\begin{tabular}{lcccccc}
\hline & $\begin{array}{l}\text { Injury } \\
\text { Grade }\end{array}$ & Age & ISS & $\begin{array}{c}\text { SBP in } \\
\text { the ED }\end{array}$ & $\begin{array}{c}\text { HR in } \\
\text { the ED }\end{array}$ & $\begin{array}{c}\text { Decline in } \\
\text { hematocrit } \\
\text { following transfer }\end{array}$ \\
\hline $\begin{array}{l}\text { Nonoperative Management } \\
(\mathbf{N}=\mathbf{8})\end{array}$ & $3.5 \pm 0.3$ & $30.9 \pm 4.7$ & $26.8 \pm 4.2$ & $115 \pm 6$ & $83 \pm 6$ & $1.0 \pm 0.3$ \\
\hline $\begin{array}{l}\text { Intervention } \\
(\mathbf{N}=\mathbf{8})\end{array}$ & $3.9 \pm 0.2$ & $38.5 \pm 8.2$ & $25.5 \pm 4.6$ & $125 \pm 10$ & $106 \pm 9^{*}$ & $5.3 \pm 2.0^{*}$ \\
\hline $\begin{array}{l}\text { ISS Injury Severity Score, SBP systolic blood pressure, HR heart rate * } p \text {-value }<0.05 \\
\text { ED Emergency Department }\end{array}$
\end{tabular}




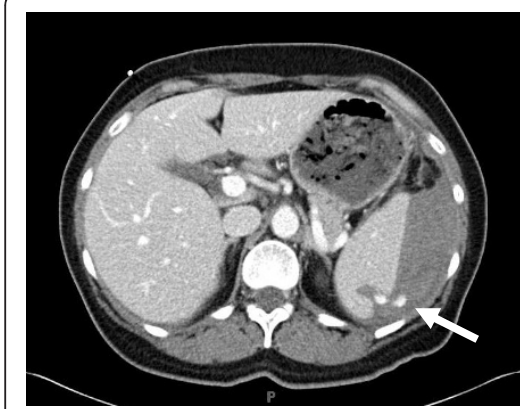

A

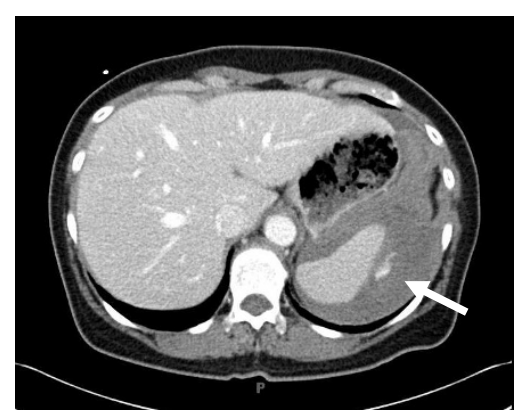

B

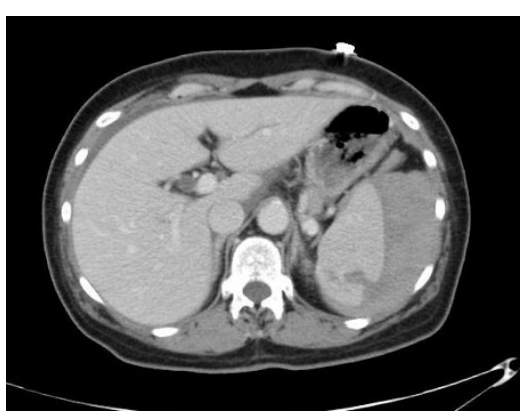

C

Figure $1 \mathrm{CT}$ scans from the outside hospital demonstrate contrast extravasation from the spleen $(\mathrm{A}, \mathrm{B})$. Repeat imaging at Denver Health reveals the blush has resolved (c).

In our experience, half of patients with a contrast blush on initial postinjury CT scan did not require intervention, either operative or catheter based, following transfer to our hospital for intended angioembolization. This number may, in fact, have been higher if the two patients who did not show evidence of extravasation at angiography but underwent empiric embolization were considered in this group rather than the treatment group. Those patients that underwent intervention had significantly higher ED heart rates and decline in their post-transfer hematocrit. Similar to our findings, Omert et al. reported that a patient's hemodynamics are more predictive of the need for intervention than contrast blush alone [15]. They describe the successful NOM of nine patients with splenic injuries and contrast blush, concluding that the mere presence of a contrast blush was not an absolute indication for intervention. Similar conclusions in children have also been reported [16]. Unlike other studies that have shown a correlation between increasing AAST splenic injury grade, increased incidence of contrast blush, and need for intervention [1], our group showed similar injury grades between those undergoing NOM and those requiring intervention.

There are inherent limitations in any retrospective evaluation. Additionally, the numbers in this series may be considered small, hence precluding broad generalization. However, this study serves to underscore that the surgical dictum, all blushes require embolization, may not be supported by scientific evidence once evaluated. This study is small due to the catchment population - only those patients with outside facility imaging demonstrating a blush associated with a splenic injury were included. We purposefully excluded those patients whose first evaluation was in our own emergency department with subsequent admission as management along the "surgical dictum" was more probable. By analyzing those patients who underwent transport times and hence permitted a repeated and delayed evaluation, gave us a time-frame without intervention. Finally, specifics of CT imaging technique at the outside hospital were not obtained, such as contrast volume, rate of infusion, slice thickness, and presence of delayed images; if the outside facility's physicians felt the imaging supported a diagnosis of a splenic blush mandating transport to a level I trauma center we felt specifics were of secondary importance.

\section{Conclusions}

With increases in technology and high resolution CT imaging, it is likely that more contrast blushes will be detected. Assuming that a hemodynamically stable patient requires angiography for investigation of a contrast blush is not based on scientific evidence. Based upon our experience, albeit limited in numbers and retrospective in nature, we do not feel evidence of contrast extravasation on initial CT imaging alone is a definitive indication for intervention. A period of close observation, serial examination, repeat laboratory evaluation, repeat FAST for those with an initial negative FAST, and selective repeat CT imaging, should be considered. A clinically based approach, similar to that used in all patients to determine operative versus NOM of blunt splenic injuries, rather than immediate angiography could avoid costly, invasive interventions and their associated sequelae. Future prospective trials would help delineate patients with splenic blushes who can be managed non-operatively, and could help develop treatment algorithms.

\section{Author details}

${ }^{1}$ From The Department of Surgery, Denver Health Medical Center, Denver CO, USA. ${ }^{2}$ Surgical Intensive Care Unit, Trauma \& Acute Care Surgery Fellowship, Department of Surgery, Denver Health Medical Center, 777 Bannock Street, MC 0206, Denver, CO 80204, USA.

\section{Authors' contributions}

Study Design: B Data Collection/Analysis/Interpretation: B, K, M. Manuscript Drafting: B, K, M. Critical Review: B, J. All authors read and approved the final manuscript. 


\section{Competing interests}

The authors declare that they have no competing interests.

Received: 17 February 2012 Accepted: 30 March 2012

Published: 30 March 2012

\section{References}

1. Schurr MJ, Fabian TC, Gavant M, et al: Management of blunt splenic trauma: computed tomographic contrast blush predicts failure of nonoperative management. J Trauma 1988, 28:828-831.

2. Federle MP, Courcoulas AP, Peitzman AB, et al: Blunt splenic injury in adults: clinical and CT criteria for management, with emphasis on active extravasation. Radiology 1998, 206:137-142.

3. Bee TK, Croce MA, Miller PR, Pritchard FE, Fabian TC: Failures of splenic nonoperative management: is the glass half empty or half full? J Trauma 2001, 50(2):230-236.

4. Haan JM, Bochicchio GV, Kramer N, Scalea TM: Nonoperative management of blunt splenic injury: a 5-year experience. J Trauma 2005, 58:492-498.

5. Wei B, Hemmila MR, Arbabi S, Taheri PA, Wahl WL: Angioembolization reduces operative intervention for blunt splenic injury. J Trauma 2008, 64:1472-1477.

6. Sclafani SJ, Shaftan GW, Scalea TM, et al: Nonoperative salvage of computed tomography-diagnosed splenic injuries: utilization of angiography for triage and embolization for hemostasis. J Trauma 1995, 39:818-827.

7. Davis KA, Fabian TC, Croce MA, et al: Improved success in nonoperative management of blunt splenic injuries: embolization of splenic artery pseudoaneurysms. J Trauma 1998, 44:1008-1015.

8. Haan JM, Biffl W, Knudson MM, et al: Splenic embolization revisited: a multicenter review. J Trauma 2004, 56:542-547.

9. Dent $D$, Alsabrook $G$, Erickson BA, et al: Blunt splenic injuries: high nonoperative management rate can be achieved with selective embolization. J Trauma 2004, 56:1063-1067.

10. Rajani RR, Claridge JA, Yowler CJ, et al: Improved outcome of adult blunt splenic injury: a cohort analysis. Surgery 2006, 140(4):625-631.

11. Moore FA, Davis JW, Moore EE Jr, Cocanour CS, West MA, McIntyre RC Jr: Western Trauma Association (WTA) critical decisions in trauma: management of adult blunt splenic trauma. J Trauma 2008, 65(5):1007-1011.

12. Wu SC, Chen RJ, Yang AD, Teng CC, Lee KH: Complications associated with embolization in the treatment of blunt splenic injury. World J Surg 2008, 32:476-482.

13. Smith HE, Biffl WL, Majercik SD, Jednacz J, Lambiase R, Cioffi WG: Splenic artery embolization: Have we gone too far? I Trauma 2006, 61(3):541-544.

14. Ekeh AP, McCarthy MC, Woods RJ, et al: Complications arising from splenic embolization after blunt splenic trauma. Am J Surg 2005, 189:335-339.

15. Omert $L A$, Salyer $D$, Dunham $C M$, Silva A, Protetch J: Implications of the 'contrast blush' finding on computed tomographic scan of the spleen in trauma. J Trauma 2001, 51(2):272-277.

16. Cloutier DR, Baird TB, Gormley P, McCarten KM, Bussey JG, Luks Fl: Pediatric splenic injuries with a contrast blush: successful nonoperative management without angiography and embolization. J Pediatr Surg 2004, 39:969-971.

doi:10.1186/1749-7922-7-8

Cite this article as: Burlew et al: Blunt trauma induced splenic blushes are not created equal. World Journal of Emergency Surgery 2012 7:8.

\section{Submit your next manuscript to BioMed Central and take full advantage of:}

- Convenient online submission

- Thorough peer review

- No space constraints or color figure charges

- Immediate publication on acceptance

- Inclusion in PubMed, CAS, Scopus and Google Scholar

- Research which is freely available for redistribution

Submit your manuscript at www.biomedcentral.com/submit
Biomed Central 